Article

\title{
Family Income at Birth and Risk of Attention Deficit Hyperactivity Disorder at Age 15: Racial Differences
}

\author{
Shervin Assari 1,2,3,*(i) and Cleopatra Howard Caldwell 1,4 \\ 1 Center for Research on Ethnicity, Culture and Health, School of Public Health, University of Michigan, \\ Ann Arbor, MI 48104, USA; cleoc@umich.edu \\ 2 Department of Psychiatry, University of Michigan, Ann Arbor, MI 48104, USA \\ 3 Department of Psychology, University of California, Los Angeles (UCLA), Los Angeles, CA 90095, USA \\ 4 Department of Health Behavior and Health Education, School of Public Health, University of Michigan, \\ Ann Arbor, MI 48104, USA \\ * Correspondence: assari@umich.edu; Tel.: +1-734-232-0445; Fax: +1-734-615-8739
}

Received: 23 October 2018; Accepted: 3 December 2018; Published: 14 January 2019

\begin{abstract}
Background: Socioeconomic status (SES) resources protect children and adults against the risk of medical and psychiatric conditions. According to the Minorities' Diminished Returns theory, however, such protective effects are systemically weaker for the members of racial and ethnic minority groups compared to Whites. Aims: Using a national data set with 15 years of follow up, we compared Black and White youth for the effects of family SES at birth on the risk of Attention Deficit Hyperactivity Disorder (ADHD) at age 15. Methods: The Fragile Families and Child Wellbeing Study (FFCWS, 1998-2016) is a longitudinal prospective study of urban youth from birth to age 15. This analysis included 2006 youth who were either White $(n=360)$ or Black $(n=1646)$. The independent variable was family income, the dependent variable was ADHD at age 15. Child gender, maternal age, and family type at birth were covariates, and race was the focal moderator. We ran logistic regressions in the overall sample and specific to race. Results: In the overall sample, high family income at birth was not associated with the risk of ADHD at age 15, independent of all covariates. Despite this relationship, we found a significant interaction between race and family income at birth on subsequent risk of ADHD, indicating a stronger effect for Whites compared to Blacks. In stratified models, we found a marginally significant protective effect of family SES against the risk of ADHD for White youths. For African American youth, on the other hand, family SES was shown to have a marginally significant risk for ADHD. Conclusions: The health gain that follows family income is smaller for Black than White families, which is in line with the Minorities' Diminished Returns. The solution to health disparities is not simply policies that aim to reduce the racial gap in SES, because various racial health disparities in the United States are not due to differential access to resources but rather the impact of these resources on health outcomes. Public policies, therefore, should go beyond equalizing access to resources and also address the structural racism and discrimination that impact Blacks' lives. Policies should fight racism and should help Black families to overcome barriers in their lives so they can gain health from their SES and social mobility. As racism is multi-level, multi-level interventions are needed to tackle diminished returns of SES.
\end{abstract}

Keywords: class; race; socioeconomic status; socioeconomic position; income; poverty status; ethnicity; Blacks; ethnicity; Attention Deficit Hyperactivity Disorder (ADHD)

\section{Introduction}

Attention Deficit Hyperactivity Disorder (ADHD) is a mental disorder with childhood onset. ADHD can persist throughout the course of life [1]. As ADHD is characterized by impulsivity and 
inattention, it causes impairment across multiple domains [2]. It increases the risk of several negative outcomes such as poor education and substance abuse [3]. Although the ADHD etiology is complex, both heritable factors [4] and environmental and social influences [5] contribute to its causation. Low socioeconomic status (SES) is one of the major risk factors for ADHD [6]. Financial difficulty, insecure housing, unmarried family type, and low maternal age at birth of child increase the risk of ADHD [7]. Among the environmental and SES risk factors, and similar to some other childhood mental health conditions $[8,9]$, poverty and financial difficulty are among the strongest risk factors for ADHD [7,10-13].

Although high SES is protective for population health [14-21], the health gain that follows SES is not identical across various social groups [22,23]. Although high family SES reports better health $[24,25]$ and financial strain and poverty increase [26] poor health outcomes, these effects are not similar for both privileged and under-privileged social groups [22,23]. In the United States, racial and ethnic minority groups show smaller health gains from the very same SES resources compared to Whites [22,23]. This is also true for income [27,28], one of the most established SES resources, which has a strong effect on the health of the population and individuals [29-33].

Although high SES tends to reflect better overall health [34-36], this protective effect varies across racial and ethnic groups [22,23,37-39]. Given that society treats social groups differently, SES has different impacts on purchasing power and access to resources and goods for various racial groups, and ultimately some groups can better translate their available SES resources into tangible outcomes compared to others [40-42]. These diminished returns may be due to the fact that upward social mobility has proven to be more difficult for Blacks compared to Whites, due to racism and segregation [22,23,43-45], or high levels of stress and discrimination faced by high SES Blacks [40].

Minorities' Diminished Returns (MDR) of SES [22] and the unequal effect of SES on health across racial groups [23] are among the neglected mechanisms that contribute to the pervasive racial gap in health. Both theoretical [22,23] and empirical [46-52] work has shown that these diminished returns are robust and can be found regardless of SES resource, health outcome, age group, setting, and cohort [43,44,46-52]. For example, MDR of SES have been shown on drinking alcohol [46], smoking [39], obesity [53], depression [47], anxiety [54], suicide [48], chronic medical conditions [47], and mortality [49-52] for Blacks as compared to Whites. An extreme example of these diminished returns is when high SES increases the risk of poor mental health for Black males $[27,47,55,56]$.

High SES is shown to more significantly reduce the risk of medical [53] and psychiatric [47] chronic conditions for Whites than Blacks. For example, the risk of depression may actually be higher, not lower in high SES Black males $[27,47,55,56]$. Similarly, high income and education reduce the risk of depression [27,47,55,56], obesity [53], and asthma [57] for White but not Black youth and children. Although asthma, obesity, and depression are all comorbidities of ADHD, we are not aware of any similar studies on the differential effects of SES indicators on the risk of ADHD.

Aims

To enhance the current knowledge regarding the applicability of MDR theory [22,23] to racial disparities in ADHD in youth, we compared Blacks and Whites who were under follow up from their birth to age 15 for the protective effect of family income at birth on the risk of ADHD at age 15 . Although we know that both race [58-60] and SES [6,7] impact the incidence and prevalence of ADHD, we are not aware of any previous longitudinal studies that have tested the multiplicative effects of race and SES on the risk of ADHD. So, it is still unclear whether it is "race or poverty" or "race and poverty" that shapes the ADHD disparities in the US. In line with theoretical [22] and empirical [57] work, we expect smaller effects of family income in terms of preventing ADHD for Black compared to White children. 


\section{Methods}

\subsection{Study Design}

The Fragile Families and Child Wellbeing Study (FFCWS; 1998-2016) is a 15-year longitudinal study that enrolled a random sample of economically fragile families from 20 US cities with a population of at least 200,000 individuals. Although a detailed description of the study design, conceptual model, sampling, methodology, and data collection of the FFCWS is available elsewhere [61-64], we provide a brief summary of the FFCWS methodology here.

\subsection{Study Sample}

The FFCW original sample included 4655 families, composed of 2407 Black, 1354 Hispanic, and 894 White families. The FFCWS oversampled non-married couples. As a result, the findings of the FFCWS are not representative of the US general population as a whole. The results are relevant to minority, non-marital, and low SES families.

\subsection{Ethical Considerations}

The Princeton University (PU) Institutional Review Board (IRB 13-1946) approved the FFCWS study protocol. All the adolescents' legal guardians, parents, and primary caregivers signed informed consent. All youth provided assent. All the participants received financial incentives to compensate for their time.

\subsection{Current Analysis and Analytical Sample}

The current analysis used data from the first and sixth waves of the study. We only included Black and White families who had data on baseline family income and youth chronic disease (ADHD) 15 years later. The analytical sample in this paper was 2006 youth who were either White $(n=360)$ or Black $(n=1646)$.

\subsection{Study Variables}

Independent Variable: Family income at birth was the main independent variable. This variable was calculated based on the family income reported by the mother. Family income was operationalized as an interval measure, with high scores indicating high SES.

Dependent Variable. Primary caregivers of the child/youth were asked: "Has a doctor or health professional ever told you that YOUTH has ADHD?" Responses included yes, no, refuse to answer, do not know.

Covariates: Child gender, family structure, and maternal age at the time of birth (wave 1) were measured as confounders. Child gender was a dichotomous variable (male 1, female 0). Maternal age was an interval variable, treated as a continuous measure. Family structure was a dichotomous variable that was calculated based on the mothers' report ( 0 not married, 1 married).

Moderator: Race/ethnicity was the focal moderator/effect modifier in the current study. Race was operationalized as a dichotomous variable, with Whites as the reference category (score 0 ) and Blacks coded as 1 .

\subsection{Data Analysis}

For our data analyses, we used Stata version 15.0 (Stata Corp; College Station, TX, USA). For univariate analysis, we reported mean and proportions in the pooled sample as well as by race/ethnicity. Taylor series linearization was applied to re-estimate the design-based standard errors (SEs). As a result, all the inferences reported here consider sampling weights. We used sub-pop survey commands. We ran our analyses in the overall sample and for each race/ethnic group. For bivariate analysis, we applied the Pearson Chi-square test as well as an independent sample $t$ test to compare 
Whites and African Americans at baseline and at age 15. For multivariable models, we used four logistic regressions. From our logistic regressions, we reported adjusted odds ratios (ORs), standard errors (SE), 95\% confidence intervals (CIs), and $p$ levels. Four logistic regression models were fitted to the data. In all of our models, ADHD at age 15 was the main dependent variable, family income was the main independent variable, while child gender, maternal age, and family type (i.e., marital status of the family at birth) were covariates. Model 1 and Model 2 were estimated in the overall sample, while the last two models were conducted for each racial/ethnic group. Model 1 did not include the interaction term; however, the second model also included a race by poverty status interaction term.

\section{Results}

\subsection{Study Participants}

This study included 2006 youth who were under follow up from their birth to age 15. Participants were either White $(n=360)$ or Black $(n=1646)$.

Table 1 provides a description of the pooled sample, as well as for each race/ethnic group. Black children had lower maternal age at birth compared to White children. Although the majority of the White children were born to families in which parents were married, most Black children were born to unmarried families. Family income was substantially lower for Black youth compared to White youth. Finally, the prevalence of ADHD at age 15 was not significantly different between White and Black youth (Table 1).

Table 1. Sociodemographic characteristics in the pooled sample and across race/ethnic groups.

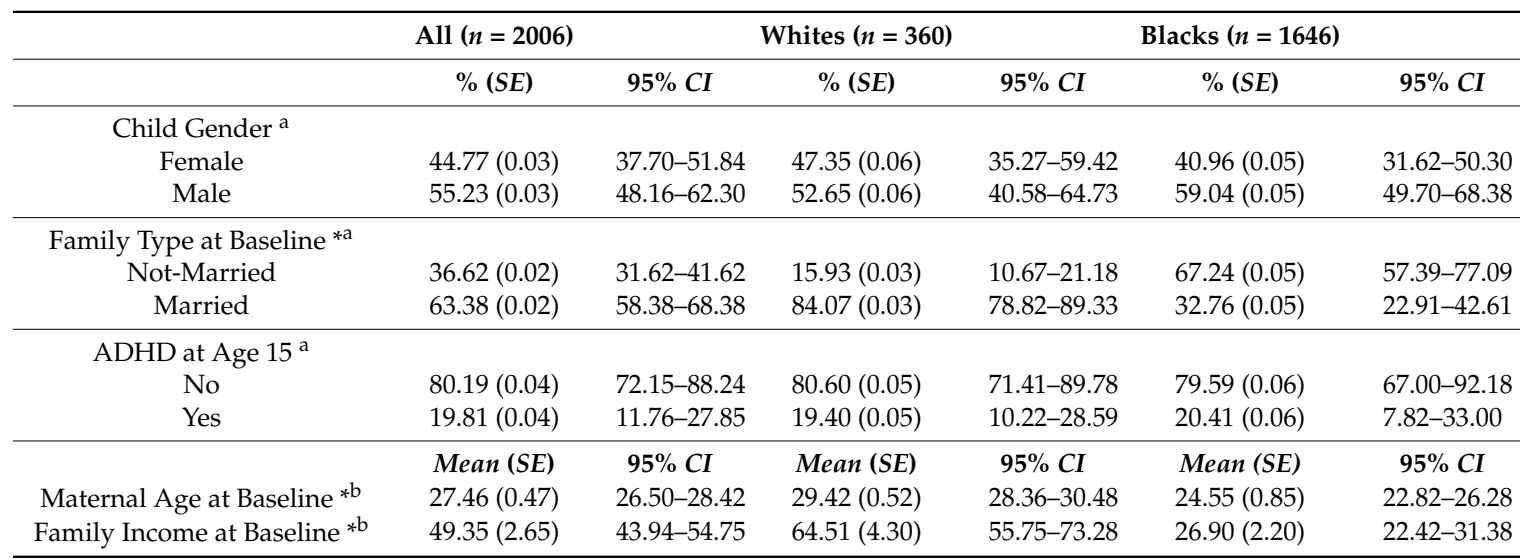

Notes: Source: Fragile Families and Child Wellbeing Study (FFCWS; 1998-2016), * $p<0.05$ for Blacks versus Whites comparisons, ${ }^{\text {a }}$ Chi Square Test, ${ }^{\mathrm{b}}$ Independent Samples $t$ Test, Attention Deficit Hyperactivity Disorder (ADHD), Standard Error (SE), Confidence Interval (CI).

\subsection{Regression Models in the Overall Sample}

Table 2 summarizes the results of Model 1 and Model 2 that were performed in the overall sample. The first model did not include any interaction term and did not show any association between family income at birth and risk of ADHD at age 15. The next model showed a significant interaction between race and family income on the risk of ADHD, indicating a significantly smaller protective effect for Blacks than Whites. 
Table 2. The results of logistic regressions in the overall sample.

\begin{tabular}{ccccc}
\hline & OR $(S E)$ & $95 \%$ CI & T & $p$ \\
\hline Model 1 (All) $(\boldsymbol{n}=$ 2006) & & & & \\
Race (Black) & $0.84(0.52)$ & $0.24-2.98$ & -0.27 & 0.787 \\
Child Gender (Male) & $2.43(1.15)$ & $0.93-6.37$ & 1.88 & 0.069 \\
Maternal Age at Baseline & $0.97(0.05)$ & $0.88-1.07$ & -0.65 & 0.519 \\
Family Type (Married) at Baseline & $1.60(1.34)$ & $0.29-8.78$ & 0.56 & 0.580 \\
Family Income at Baseline & $0.99(0.01)$ & $0.98-1.01$ & -0.95 & 0.349 \\
Intercept & $0.37(0.48)$ & $0.03-5.13$ & -0.77 & 0.446 \\
\hline Model 2 (All) $(\boldsymbol{n}=$ 2006) & & & & \\
Race (Black) & $0.22(0.14)$ & $0.06-0.79$ & -2.41 & 0.022 \\
Child Gender (Male) & $2.52(1.23)$ & $0.93-6.79$ & 1.90 & 0.067 \\
Maternal Age at Baseline & $0.97(0.05)$ & $0.87-1.08$ & -0.60 & 0.550 \\
Family Type (Married) at Baseline & $1.43(1.11)$ & $0.30-6.94$ & 0.46 & 0.646 \\
Family Income at Baseline & $0.98(0.01)$ & $0.96-1.00$ & -1.86 & 0.072 \\
Family Income at Baseline $\times$ Race & $1.03(0.01)$ & $1.01-1.06$ & 2.99 & 0.005 \\
Intercept & $0.71(0.97)$ & $0.04-11.47$ & -0.25 & 0.805 \\
\hline
\end{tabular}

Notes: Source: Fragile Families and Child Wellbeing Study (FFCWS; 1998-2016), Outcome: Attention Deficit

Hyperactivity Disorder (ADHD) at age 15, Confidence Interval (CI).

\subsection{Regression Models Specific to Each Race}

Table 3 summarizes the results of Model 3 and Model 4 in racial groups. Our stratified regression models revealed a marginally significant protective effect of family income against the risk of ADHD for White, but a marginally significant risk effect for Black youth (Table 3).

Table 3. The results of two logistic regression models by race.

\begin{tabular}{ccccc}
\hline & OR $($ SE) & $\mathbf{9 5 \%} \mathbf{C I}$ & $\boldsymbol{t}$ & $\boldsymbol{p}$ \\
\hline Model 3 (Whites) $(\boldsymbol{n = 3 6 0 )}$ & & & & \\
Child Gender (Male) & $2.07(1.39)$ & $0.53-8.11$ & 1.08 & 0.287 \\
Maternal Age at Baseline & $0.97(0.06)$ & $0.85-1.10$ & -0.50 & 0.619 \\
Family Type (Married) at Baseline & $1.26(1.18)$ & $0.19-8.49$ & 0.25 & 0.806 \\
Family Income at Baseline & $0.98(0.01)$ & $0.96-1.00$ & -1.78 & 0.084 \\
Intercept & $0.88(1.50)$ & $0.03-28.00$ & -0.07 & 0.943 \\
\hline Model 4 (Blacks) $(\boldsymbol{n}=\mathbf{1 6 4 6 )}$ & & & & \\
Child Gender (Male) & $3.63(1.52)$ & $1.55-8.51$ & 3.08 & 0.004 \\
Maternal Age at Baseline & $0.98(0.05)$ & $0.87-1.09$ & -0.41 & 0.685 \\
Family Type (Married) at Baseline & $1.48(1.32)$ & $0.24-9.15$ & 0.44 & 0.665 \\
Family Income at Baseline & $1.02(0.01)$ & $1.00-1.03$ & 2.38 & 0.024 \\
Intercept & $0.10(0.12)$ & $0.01-1.08$ & -1.97 & 0.058 \\
\hline
\end{tabular}

Notes: Source: Fragile Families and Child Wellbeing Study (FFCWS; 1998-2016), Outcome: Attention Deficit Hyperactivity Disorder (ADHD) at age 15, Confidence Interval (CI), Odds Ratio (OR).

\section{Discussion}

The current study showed a differential effect of family income at birth on the risk of ADHD at age 15 for White and Black youth. High family income at birth reduced ADHD risk for White but not Black youth at age 15 .

In the National Survey of Children's Health (NSCH, 2003-2004), which included 86,537 Black and White children (17 years old or younger), a higher SES was associated with a lower risk of childhood asthma for both Whites and Blacks. The magnitude of this protective effect was considerably larger for White compared to Black children and youth [57]. Similar patterns are shown for depression $[27,47,55,56]$, obesity [53], and asthma [57], meaning that SES better protects Whites than Blacks for several mental health and health outcomes. 
The protective effect of high family income against ADHD for White youth is in line with previous studies [6,7], showing that there is an economic gradient in the epidemiology of ADHD and other health outcomes. The same pattern is shown for other chronic conditions [65]. This protection is, however, missing for Blacks. There are multiple studies showing that high SES of the family generates fewer health protections for Black than White children. A series of analyses on the Fragile Families and Child Wellbeing Study (FFCWS) data documented Black-White differences in gaining health from family SES. The effects of family SES at birth on future BMI [53], self-rated health [66], impulsivity [67], and chronic disease [57] are smaller for Blacks than Whites, which is in line with the MDR theory [53].

The finding that equal family income at birth generates unequal protection for White and Black youth is similar to the findings of a large number of studies that have documented diminished effects of family SES on obesity, impulse control, subjective health, and asthma $[53,57,66,67]$. This is in part because educated Blacks are more likely to remain poor compared to educated Whites $[68,69]$.

Although MDR theory is well supported by empirical data [22,23], fewer studies have focused on children and youth $[70,71]$ as compared to adults [41,47,48,72]. Among the various possible underlying mechanisms that may cause smaller health gains of SES among Blacks than Whites, childhood characteristics and differential exposure early in life may play some role [53]. Smaller health gains from family SES at birth may be one of the reasons Black children suffer worse health outcomes than White children $[67,68]$. This mechanism is different from Black-White mean difference in exposures to risk factors and access to resources and buffers such as the health care system [73,74]. In this view, socially, economically, and politically disadvantaged minority groups unequally gain from their very same resources compared to the economically, politically, and socially privileged majority group.

Diminished health effects of SES for Blacks do not suggest that Black families are less able to effectively take advantage of their human and economic resources and turn them into tangible outcomes. Such an argument would be blaming the victim. Reduced gains are not because of their culture, but because they have been marginalized, stigmatized, and treated poorly in this society. Not only do Black individuals have a lower chance of upward social mobility, they do not enjoy similar benefits from their social mobility [43-45]. Such diminished returns are a function of racism and discrimination [75], rather than the culture of poverty [76]. These diminished returns may be a result of being victimized and stigmatized over generations. Some of the minorities may feel some pressure to appear strong, wealthy, and successful [77-87], which may have an impact on their children. Instead of individual behaviors, choices, and preferences contributing to success, it is the US social structure that can cause MDR [22,23]. Due to segregation and institutional and structural racism, Black individuals face far more societal barriers in their daily lives that hinder them from obtaining the most possible health gains from each available resource across generations.

It is not Black families, but the current US political and social system that has failed, resulting in differential patterns of health and mental health outcomes [22,23]. US society consistently demands more of high SES Blacks so that they pay an extra psychological and physiological cost for their success. In race-aware societies that treat people differently based on their skin color, upward social mobility is not similarly feasible for all racial groups. Blacks pay far more social, psychological, and physiological costs for the same social success compared to Whites [43,44]. The current political, economic, and social systems in the US are designed to maximize the gains of privileged groups. This, of course, comes with costs to non-White groups [22,23]. This is one of the many reasons why closing the SES gap does not close the stubborn Black-White health gap.

We used family income at birth instead of income at age 15 for several reasons. First, we were particularly interested in causal effects, which requires temporal order (exposure occurs before outcome). We preferred to test the consequence of exposure 15 years later. In addition, FFCWS is one of the few long-term longitudinal steadies and we wanted to take advantage of the longitudinal design of the study. Furthermore, most of the literature is on cross-sectional associations rather than on longitudinal effects. So, with this decision, our paper made a unique contribution to the field. Finally, the diminished returns of income and other SES require time to develop. That is, over the 
15 years from birth, the groups develop differences in the effects of SES, which may not be present when cross-sectional associations are tested. This is in line with a cumulative disadvantage approach, which is also in line with the life course developmental approach. Finally, we were interested in the intergenerational transmission of diminished returns of SES. As a result, we used family income at birth instead of the SES of the participant at age 15.

\section{Limitations}

The study had a few limitations. First, similar to any other long-term cohort, the study had a loss to follow up and attrition, which was not at random. The outcome was not confirmed based on administrative data, but the self-report of parents and caregivers. In addition, the FFCWS does not have any variable that reflects the possibility of heredity of ADHD. We have added this as a missing covariate in this study's limitations section. Finally, the results of our analysis should be interpreted with caution because: 1) there is only a limited number of controls; and 2) the focus is exclusively on Black-White gaps in ADHD, while other types of categorical comparisons are not the subject of this study (for example, the FFCWS contains a relatively large sample of Hispanics, but the authors did not include this group in their analysis). Therefore, the generalization of findings may be limited. Despite these limitations, the results make a unique contribution as very few studies, if any, have focused on the diminished returns of SES indicators on ADHD.

\section{Conclusions}

The protective effect of family income at birth in lowering the risk of ADHD at age 15 differs for White and Black youth. This is a longitudinal replication of a cross-sectional finding [57], suggesting that there are more high SES Blacks with ADHD than high SES Whites with the same condition. Diminished returns of SES is a systemically neglected contributor to racial gaps in health in the US. Future research should decompose the effects of structural racism, interpersonal discrimination, stress, environmental exposures, neighborhood SES, and societal barriers that may have some role in these heterogenetic associations. At the same time, public, social, and economic policies should go beyond equalizing SES and income and instead equalize the impact of such resources. Policies should explore multi-level solutions that eliminate or at least reduce the MDR of SES resources. A realistic solution to the racial gap in health requires the joint consideration of race and SES, which means not ignoring the systemic interactions between race and SES and their role in shaping health disparities.

Author Contributions: S.A. designed the current work, analyzed the data, and drafted the manuscript. C.H.C. contributed to the interpretation of the findings, drafts, and revisions. Both authors approved the final draft of the paper.

Funding: Shervin Assari is in part supported by the grants 4P60MD006923-05 (National Institute on Minority Health and Health Disparities; NIMHD; PI = Vickie Mays), D084526-03 (National Institute of Child Health and Human Development; NICHD), CA201415 02 (the National Cancer Institute; NCI; Co-PI = Ritesh Mistry), and DA035811-05 (National Institute on Drug Abuse; NIDA; PI = Marc Zimmerman).

Acknowledgments: Research reported in this publication was supported by the Eunice Kennedy Shriver National Institute of Child Health and Human Development (NICHD) of the National Institutes of Health under award numbers R01HD36916, R01HD39135, and R01HD40421, as well as a consortium of private foundations. The content is solely the responsibility of the authors and does not necessarily represent the official views of the National Institutes of Health. We thank Hamid Helmi, faculty at Wayne State University, for his contribution to the paper.

Conflicts of Interest: Authors declare that they have no conflict of interest.

\section{References}

1. Shah, P.J.; Morton, M.J. Adults with attention-deficit hyperactivity disorder-diagnosis or normality? Br. J. Psychiatry 2013, 203, 317-319. [CrossRef] [PubMed]

2. American Psychiatric Association. The Diagnostic and Statistical Manual of Mental Disorders, 5th ed.; American Psychiatric Association: Washington, DC, WA, USA, 2013. 
3. Bernfort, L.; Nordfeldt, S.; Persson, J. ADHD from a socio-economic perspective. Acta Paediatr. 2008, 97, 239-245. [CrossRef] [PubMed]

4. Faraone, S.V.; Perlis, R.H.; Doyle, A.E.; Smoller, J.W.; Goralnick, J.J.; Holmgren, M.A.; Sklar, P. Molecular genetics of attention-deficit/hyperactivity disorder. Biol. Psychiatry 2005, 57, 1313-1323. [CrossRef] [PubMed]

5. Thapar, A.; Cooper, M.; Eyre, O.; Langley, K. Practitioner Review: What have we learnt about the causes of ADHD? J. Child Psychol. Psychiatry 2013, 54, 3-16. [CrossRef] [PubMed]

6. Russell, G.; Ford, T.; Rosenberg, R.; Kelly, S. The association of attention deficit hyperactivity disorder with socioeconomic disadvantage: Alternative explanations and evidence. J. Child Psychol. Psychiatry 2014, 55, 436-445. [CrossRef] [PubMed]

7. Russell, A.E.; Ford, T.; Russell, G. Socioeconomic Associations with ADHD: Findings from a mediation analysis. PLoS ONE 2015, 10, e0128248. [CrossRef]

8. Petrill, S.A.; Pike, A.; Price, T.; Plomin, R. Chaos in the home and socioeconomic status are associated with cognitive development in early childhood: Environmental mediators identified in a genetic design. Intelligence 2004, 32, 445-460. [CrossRef]

9. Reiss, F. Socioeconomic inequalities and mental health problems in children and adolescents: A systematic review. Soc. Sci. Med. 2013, 90, 24-31. [CrossRef]

10. Russell, A.E.; Ford, T.; Williams, R.; Russell, G. The association between socioeconomic disadvantage and attention deficit/hyperactivity disorder (ADHD): A systematic review. Child Psychiatry Hum. Dev. 2016, 47, 440-458. [CrossRef]

11. Russell, A.E.; Ford, T.; Russell, G. The relationship between financial difficulty and childhood symptoms of attention deficit/hyperactivity disorder: A UK longitudinal cohort study. Soc Psychiatry Psychiatr Epidemiol. 2018, 53, 33-44. [CrossRef]

12. Rowland, A.S.; Skipper, B.J.; Rabiner, D.L.; Qeadan, F.; Campbell, R.A.; Naftel, A.J.; Umbach, D.M. Attention-deficit/hyperactivity disorder (ADHD): Interaction between socioeconomic status and parental history of ADHD determines prevalence. J. Child Psychol. Psychiatry 2018, 59, 213-222. [CrossRef] [PubMed]

13. Lingineni, R.K.; Biswa, S.; Ahmad, N.; Jackson, B.E.; Bae, S.; Singh, K.P. Factors associated with attention deficit/hyperactivity disorder among US children: Results from a national survey. BMC Pediatr. 2012, 12, 50. [CrossRef]

14. American Lung Association (ALA). Socioeconomic and Racial Asthma Disparities in Asthma. Available online: www.lung.org/local-content/illinois/documents/socioeconomic-asthma-disparities.pdf (accessed on 1 January 2018).

15. Mirowsky, J.; Ross, C.E. Education, Social Status, and Health; Aldine de Gruyter: New York, NY, USA, 2003.

16. Bowen, M.E.; González, H.M. Childhood socioeconomic position and disability in later life: Results of the health and retirement study. Am. J. Public Health 2010, 100, S197-S203. [CrossRef] [PubMed]

17. Herd, P.; Goesling, B.; House, J.S. Socioeconomic position and health: The differential effects of education versus income on the onset versus progression of health problems. J. Health Soc. Behav. 2007, 48, 223-238. [CrossRef] [PubMed]

18. Kim, J. Intercohort trends in the relationship between education and health: Examining physical impairment and depressive symptomatology. J. Aging Health 2008, 20, 671-693. [CrossRef] [PubMed]

19. Ross, C.E.; Mirowsky, J. Refining the association between education and health: The effects of quantity, credential, and selectivity. Demography 1999, 36, 445-460. [CrossRef]

20. Leopold, L.; Engelhardt, H. Education and physical health trajectories in old age. Evidence from the Survey of Health, Ageing and Retirement in Europe (SHARE). Int. J. Public Health 2013, 58, 23-31. [CrossRef]

21. Johnson-Lawrence, V.D.; Griffith, D.M.; Watkins, D.C. The effects of race, ethnicity and mood/anxiety disorders on the chronic physical health conditions of men from a national sample. Am. J. Mens Health 2013, 7,58S-67S. [CrossRef]

22. Assari, S. Unequal gain of equal resources across racial groups. Int. J. Health Policy Manag. 2017, 6, 1-9. [CrossRef]

23. Assari, S. Health disparities due to minorities diminished return: Policy solutions. Soc. Issues Policy Rev. 2018, 12, 112-145. [CrossRef]

24. Alaimo, K.; Olson, C.M.; Frongillo, E.A., Jr.; Briefel, R.R. Food insufficiency, family income, and health in US preschool and school-aged children. Am. J. Public Health 2001, 91, 781-786. [PubMed] 
25. Shah, C.P.; Kahan, M.; Krauser, J. The health of children of low-income families. CMAJ 1987, 137, 485-490. [PubMed]

26. Chen, E. Why socioeconomic status affects the health of children: A psychosocial perspective. Curr. Dir. Psychol. Sci. 2004, 13, 112-115. [CrossRef]

27. Assari, S.; Caldwell, C.H. High risk of depression in high-income African American boys. J. Racial Ethn. Health Disparities 2017, 5, 808-819. [CrossRef] [PubMed]

28. Assari, S. High income protects whites but not African Americans against risk of depression. Healthcare 2018, 6, 37. [CrossRef] [PubMed]

29. Marmot, M. The influence of income on health: Views of an epidemiologist. Health Aff. 2002, 21, 31-46. [CrossRef]

30. Deaton, A. Health, income, and inequality. NBER Reporter: Research Summary Spring 2003. Available online: https:/ / www.nber.org/reporter/spring03/health.html (accessed on 3 January 2019).

31. Lynch, J.; Smith, G.D.; Harper, S.; Hillemeier, M.; Ross, N.; Kaplan, G.A.; Wolfson, M. Is income inequality a determinant of population health? Part 1. A systematic review. Milbank Q. 2004, 82, 5-99. [CrossRef]

32. Ecob, R.; Smith, G.D. Income and health: What is the nature of the relationship? Soc. Sci. Med. 1999, 48, 693-705. [CrossRef]

33. Lynch, J.; Smith, G.D. Commentary: Income inequality and health: The end of the story? Int. J. Epidemiol. 2002, 31, 549-551. [CrossRef]

34. Phelan, J.C.; Link, B.G.; Tehranifar, P. Social conditions as fundamental causes of health inequalities: Theory, evidence, and policy implications. J. Health Soc. Behav. 2010, 51, S28-S40. [CrossRef]

35. Link, B.G.; Phelan, J. Social Conditions as Fundamental Causes of Health Inequalities. In Handbook of Medical Sociology, 6th ed.; Bird, C.E., Conrad, P., Fremont, A.M., Timmermans, S., Eds.; Vanderbilt University Press: Nashville, TN, USA, 2010; pp. 3-17.

36. Link, B.; Phelan, J. Social conditions as fundamental causes of disease. J. Health Soc. Behav. 1995, 36, 80-94. [CrossRef]

37. Assari, S. Social Determinants of depression: The intersections of race, gender, and socioeconomic status. Brain Sci. 2017, 7, 156. [CrossRef] [PubMed]

38. Assari, S. Socioeconomic status and self-rated oral health; diminished return among Hispanic Whites. Dent. J. 2018, 6, 11. [CrossRef] [PubMed]

39. Assari, S.; Mistry, R. Educational Attainment and smoking status in a national sample of american adults; evidence for the blacks' diminished return. Int. J. Environ. Res. Public Health 2018, 15, 763. [CrossRef] [PubMed]

40. Hudson, D.L.; Bullard, K.M.; Neighbors, H.W.; Geronimus, A.T.; Yang, J.; Jackson, J.S. Are benefits conferred with greater socioeconomic position undermined by racial discrimination among African American men? J. Mens Health 2012, 9, 127-136. [CrossRef] [PubMed]

41. Assari, S.; Nikahd, A.; Malekahmadi, M.R.; Lankarani, M.M.; Zamanian, H. Race by gender group differences in the protective effects of socioeconomic factors against sustained health problems across five domains. J. Racial Ethn. Health Disparities 2016, 4, 884-894. [CrossRef] [PubMed]

42. Hudson, D.L. Race, Socioeconomic Position and Depression: The Mental Health Costs of Upward Mobility. Ph.D. Thesis, The University of Michigan, Ann Arbor, MI, USA, 2009.

43. Fuller-Rowell, T.E.; Doan, S.N. The social costs of academic success across ethnic groups. Child Dev. 2010, 81, 1696-1713. [CrossRef]

44. Fuller-Rowell, T.E.; Curtis, D.S.; Doan, S.N.; Coe, C.L. Racial disparities in the health benefits of educational attainment: A study of inflammatory trajectories among African American and white adults. Psychosom. Med. 2015, 77, 33-40. [CrossRef]

45. Assari, S. Race, intergenerational social mobility and stressful life events. Behav. Sci. 2018, 8, 86. [CrossRef]

46. Hummer, R.A.; Lariscy, J.T. Educational Attainment and Adult Mortality; International Handbook of Adult Mortality; Springer: Berlin/Heidelberg, Germany, 2011; pp. 241-261.

47. Assari, S. Combined Racial and Gender Differences in the Long-Term Predictive Role of Education on Depressive Symptoms and Chronic Medical Conditions. J. Racial Ethn. Health Disparities 2016, 4, 385-396. [CrossRef] 
48. Assari, S. Ethnic and gender differences in additive effects of socio-economics, psychiatric disorders, and subjective religiosity on suicidal ideation among Blacks. Int. J. Prev. Med. 2015, 6, 53. [CrossRef] [PubMed]

49. Hayward, M.D.; Hummer, R.A.; Sasson, I. Trends and group differences in the association between educational attainment and US adult mortality: Implications for understanding education's causal influence. Soc. Sci. Med. 2015, 127, 8-18. [CrossRef] [PubMed]

50. Assari, S.; Lankarani, M.M. Race and urbanity alter the protective effect of education but not income on mortality. Front. Public Health 2016, 4, 100. [CrossRef]

51. Backlund, E.; Sorlie, P.D.; Johnson, N.J. A comparison of the relationships of education and income with mortality: The National Longitudinal Mortality Study. Soc. Sci. Med. 1999, 49, 1373-1384. [CrossRef]

52. Everett, B.G.; Rehkopf, D.H.; Rogers, R.G. The nonlinear relationship between education and mortality: An examination of cohort, race/ethnic, and gender differences. Popul. Res. Policy Rev. 2013, 32, 893-917. [CrossRef] [PubMed]

53. Assari, S.; Thomas, A.; Caldwell, C.H.; Mincy, R.B. Blacks' diminished health return of family structure and socioeconomic status; 15 years of follow-up of a national urban sample of youth. J. Urban Health 2018, 95, 21-35. [CrossRef] [PubMed]

54. Assari, S.; Caldwell, C.H.; Zimmerman, M.A. Family structure and subsequent anxiety symptoms; minorities' diminished return. Brain Sci. 2018, 8, 97. [CrossRef]

55. Hudson, D.L.; Neighbors, H.W.; Geronimus, A.T.; Jackson, J.S. The relationship between socioeconomic position and depression among a US nationally representative sample of African Americans. Soc. Psychiatry Psychiatr. Epidemiol. 2012, 47, 373-381. [CrossRef]

56. Watkins, D.C.; Green, B.L.; Rivers, B.M.; Rowell, K.L. Depression and black men: Implications for future research. J. Mens Health Gend. 2006, 3, 227-235. [CrossRef]

57. Assari, S.; Moghani Lankarani, M. Poverty status and childhood asthma in white and black families: National survey of children's health. Healthcare 2018, 6, 62. [CrossRef]

58. Coker, T.R.; Elliott, M.N.; Toomey, S.L.; Schwebel, D.C.; Cuccaro, P.; Tortolero Emery, S.; Davies, S.L.; Visser, S.N.; Schuster, M.A. Racial and ethnic disparities in ADHD diagnosis and treatment. Pediatrics 2016, 138, e20160407. [CrossRef] [PubMed]

59. Pastor, P.N.; Reuben, C.A. Racial and ethnic differences in ADHD and LD in young school-age children: Parental reports in the National Health Interview Survey. Public Health Rep. 2005, 120, 383-392. [CrossRef] [PubMed]

60. Malat, J.; Oh, H.J.; Hamilton, M.A. Poverty experience, race, and child health. Public Health Rep. 2005, 120, 442-447. [CrossRef] [PubMed]

61. Carlson, B.L. Fragile Families \& Child Wellbeing Study: Methodology for Constructing Mother, Father, and Couple Weights for Core Telephone Public Survey Data Waves 1-4; Mathematica Policy Research: Washington, DC, USA, 2008.

62. McLanahan, S.; Garfinkel, I.; Waller, M. Fragile Families and Child Wellbeing Study; Eunice Kennedy Shriver National Institute of Child Health and Human Development (NICHD): 2000; Public Policy Institute of California: San Francisco, CA, USA, 2000.

63. Waldfogel, J.; Craigie, T.A.; Brooks-Gunn, J. Fragile families and child wellbeing. Future Child. 2010, 20, 87-112. [CrossRef] [PubMed]

64. McLanahan, S.; Garfinkel, I.; Reichman, N.; Teitler, J.; Carlson, M.; Audigier, C.N. The Fragile Families and Child Wellbeing Study: Baseline National Report; Center for Research on Child Wellbeing, Princeton University: Princeton, NJ, USA, 2003.

65. Case, A.; Darren, L.; Christina, P. Economic status and health in childhood: The origins of the gradient. Am. Econ. Rev. 2002, 92, 1308-1334. [CrossRef] [PubMed]

66. Assari, S.; Caldwell, C.H.; Mincy, R.B. Maternal Educational Attainment at Birth Promotes Future Self-Rated Health of White but Not Black Youth: A 15-Year Cohort of a National Sample. J. Clin. Med. 2018, 7, 93. [CrossRef] [PubMed]

67. Assari, S.; Caldwell, C.H.; Mincy, R. Family socioeconomic status at birth and youth impulsivity at age 15; Blacks' diminished return. Children 2018, 5, 58. [CrossRef] [PubMed]

68. Assari, S. Parental Education Better Helps White than Black Families Escape Poverty: National Survey of Children's Health. Economies 2018, 6, 30. [CrossRef] 
69. Assari, S. Diminished economic return of socioeconomic status for black families. Soc. Sci. 2018, 7, 74 . [CrossRef]

70. Smith, S.M.; Sun, R. Racial discrimination and depressive symptomology: exploring gender and socioeconomic variations among African American parent-child dyads. Fire!!! 2014, 3, 130-159. [CrossRef]

71. Hudson, D.L.; Puterman, E.; Bibbins-Domingo, K.; Matthews, K.A.; Adler, N.E. Race, life course socioeconomic position, racial discrimination, depressive symptoms and self-rated health. Soc. Sci. Med. 2013, 97, 7-14. [CrossRef]

72. Assari, S.; Lankarani, M.M. Education and Alcohol Consumption among Older Americans; Black-White Differences. Front. Public Health 2016, 4, 67. [CrossRef]

73. Nelson, A. Unequal treatment: Confronting racial and ethnic disparities in health care. J. Natl. Med. Assoc. 2002, 94, 666-668. [PubMed]

74. Vokó, Z.; Csépe, P.; Németh, R.; Kósa, K.; Kósa, Z.; Széles, G.; Ádány, R. Does socioeconomic status fully mediate the effect of ethnicity on the health of Roma people in Hungary? J. Epidemiol. Community Health 2009, 63, 455-460. [CrossRef]

75. Adler, N.E.; Stewart, J. Reducing obesity: Motivating action while not blaming the victim. Milbank Q. 2009, 87, 49-70. [CrossRef] [PubMed]

76. Jones, R.K.; Luo, Y. The culture of poverty and African-American culture: An empirical assessment. Sociol. Perspect. 1999, 42, 439-458. [CrossRef]

77. Moav, O.; Neeman, Z. Bling Bling, Human Capital, and Poverty. In Proceedings of the European Summer Symposium in International Macroeconomics (ESSIM), Tarragona, Spain, 20-25 May 2008.

78. Betsey, C.L. Black-white differences in consumption: An update and some policy implications. Rev. Black Political Econ. 2014, 41, 259-270. [CrossRef]

79. Heath, B.J. Buttons, Beads, and Buckles: Contextualizing Adornment within the Bounds of Slavery. In Historical Archaeology, Identity Formation, and the Interpretation of Ethnicity; Franklin, M., Fesler, G., Eds.; Colonial Williamsburg Foundation: Williamsburg, VA, USA, 1999; pp. 47-69.

80. Omori, M.; Smith, D.T. The Impact of Socioeconomic Status and Metropolitan Area Racial Composition on Visible Consumption Among Whites and Racial/Ethnic Minorities. Race Soc. Prob. 2015, 7, 169-180. [CrossRef]

81. Patton, T.O. Hey girl, am I more than my hair: African American women and their struggles with beauty, body image, and hair. NWSA J. 2006, 2, 24-51. [CrossRef]

82. Russell, A.E. Material culture and African-American spirituality at the Hermitage. Hist. Archaeol. 1997, 31, 63-80. [CrossRef]

83. O'Neal, G.S. African American women's professional dress as expression of ethnicity. J. Fam. Consum. Sci. 1998, 90, 28.

84. O'Neal, G.S. African-American aesthetic of dress: Current manifestations. Cloth. Text. Res. J. 1998, 16, 167-175. [CrossRef]

85. Bellinger, W. Why African American women try to obtain 'good hair'. Sociol. Viewp. 2007, 23, 63.

86. Jacobs-Huey, L. From the Kitchen to the Parlor: Language and Becoming in African American Women's Hair Care; Oxford University Press: Oxford, UK, 2006.

87. Thompson, C. Black women, beauty, and hair as a matter of being. Women's Stud. 2009, 38, 831-856. [CrossRef]

(C) 2019 by the authors. Licensee MDPI, Basel, Switzerland. This article is an open access article distributed under the terms and conditions of the Creative Commons Attribution (CC BY) license (http:/ / creativecommons.org/licenses/by/4.0/). 